\title{
Research on Appraisal System of Procurator Performance by Using High-Order CFA Model
}

\author{
Yong-mao Huang ${ }^{1,2}$ \\ ${ }^{1}$ School of Management, Jiangsu University, Zhenjiang 212013, China \\ ${ }^{2}$ People's Procuratorate of Jingdezhen, JiangXi, Jingdezhen 333000, China \\ Correspondence should be addressed to Yong-mao Huang; huangyongmao12@163.com
}

Received 9 June 2014; Accepted 15 July 2014; Published 13 August 2014

Academic Editor: Jianguo Du

Copyright (c) 2014 Yong-mao Huang. This is an open access article distributed under the Creative Commons Attribution License, which permits unrestricted use, distribution, and reproduction in any medium, provided the original work is properly cited.

\begin{abstract}
The prosecutor is the main body of procuratorial organs. The performance appraisal system plays an important role in promoting the work efficiency of procurator. In this paper, we establish the performance appraisal system of procurators by high-order confirmatory factor analysis method and evaluate procurators' performance by fuzzy comprehensive evaluation method based on the 360 degrees. The results have some help to performance management of procuratorial organs.
\end{abstract}

\section{Introduction}

Procurator is the principal and dominant part for procuratorial organs to conduct procuratorial business and perform its functions. The establishment of a scientific and rational appraisal system will mobilize their enthusiasm, raise their work efficiency, and increase the whole procuratorial organ's work level. The existing documents, law rules, and regulations serve as basis for the establishment of the evaluation system of procurators. However, from current practical evaluation of procuratorial organs, there are prominent problems in setting targets, selecting evaluation indicators, and applying evaluation results and further improvements are needed. Many existing papers have discussed this topic such as Bouskila-Yam and Kluger (2011) [1], Jin (2010) [2], and Samuel et al. (2014) [3]. However, most of them are qualitative researches and quantitative researches are less. Given this, this paper deploys the cross validation of EFA and CFA to establish structure of the performance evaluation system to make the system more reasonable on the basis of related performance evaluation theory. This is not frequently used in other papers about the same topic and we will use fuzzy comprehensive evaluation to make instance analysis based on full circle appraisal.

\section{Acquire Appraisal Index}

The Article 26 of Law of Procurator stipulates that procurator appraisal includes their job performance, ideology and morality, professional skill and theoretical level of law, working attitude, and working style. And the focus lies in their job performance. Guided by this requirement, the research group has invited seven procurators in leadership position from a procuratorial organ in JiangXi in depth interview. At first, the compere introduces the purpose and requirements about this interview and invites them to analyze and discuss their work selectively. Based on related theories of performance appraisal system [4-8], we can explain performance from conduct, result, and capability. According to the three dimensionalities, we can acquire thirty-two initial evaluation factors, presented by $a_{1} \sim a_{32}[9,10]$.

2.1. Initial Evaluation Elements Based on Conduct. These include (1) Job responsibility $\left(a_{1}\right)$; (2) observance of procedural law $\left(a_{2}\right)$; (3) work initiative and enthusiasm $\left(a_{3}\right) ;(4)$ observance of business specification $\left(a_{4}\right)$; $(5)$ observance of "Responsibilities Certificate for Ethnical Members of CPC" $\left(a_{5}\right)$; (6) team spirit $\left(a_{6}\right)$; (7) observance of related prohibitions $\left(a_{7}\right)$; (8) refusal of gifts and bribery $\left(a_{8}\right) ;(9)$ political thoughts $\left(a_{9}\right) ;(10)$ political theory level $\left(a_{10}\right) ;(11)$ outlook 
of right and wrong and outlook of values $\left(a_{11}\right)$; (12) work organization $\left(a_{12}\right)$; and (13) deployment of effective methods $\left(a_{13}\right)$.

2.2. Initial Evaluation Elements Based on Results. These include (1) completing required work load $\left(a_{14}\right)$; (2) fulfilling duties and responsibilities as required $\left(a_{15}\right) ;(3)$ mistaken rate $\left(a_{16}\right)$; (4) the satisfaction degree of the social public $\left(a_{17}\right)$; (5) saving litigation costs $\left(a_{18}\right)$; $(6)$ meeting targets and requirements of job performance $\left(a_{19}\right)$; and (7) saving economic costs for the country $\left(a_{20}\right)$.

2.3. Initial Evaluation Elements Based on Capability. These include (1) awareness and capability to accept professional training $\left(a_{21}\right)$; (2) professional techniques and capability $\left(a_{22}\right)$; (3) capability to deal with accidents $\left(a_{23}\right)$; (4) capability to cooperate $\left(a_{24}\right)$; (5) professional knowledge level $\left(a_{25}\right) ;(6)$ capability to comprehend and analyze $\left(a_{26}\right) ;(7)$ proficiency of professional works $\left(a_{27}\right)$; $(8)$ ability to apply new knowledge and accommodate new fields $\left(a_{28}\right)$; (9) mastering foreign language and computer $\left(a_{29}\right) ;(10)$ capability to manage $\left(a_{30}\right)$; (11) capability to make observance and discovery $\left(a_{31}\right)$; and (12) oral expression and writing $\left(a_{32}\right)$.

\section{Design Appraisal Index System}

3.1. Determine the Structure of Appraisal Index System. We use EFA to further refine initial appraisal factors and work out the structure of appraisal index system. Based on initial appraisal factors, we designed the initial questionnaire on the basis of Likert scale and surveyed 100 procurators. We have recycled 88 valid samples and the valid return rate is $88 \%$.

After reliability test, we figure out that Cronbach's $\alpha$ is 0.951 , larger than the fundamental reliability requirements 0.7. So the overall reliability result is satisfactory. The outcome of $\mathrm{KMO}$ analysis is 0.860 , larger than the fundamental requirement 0.7. $\chi^{2}$ in Bartlett test of sphericity is 2087 and the significance level is 0.000 , smaller than 0.01 . These show that the questionnaire is appropriate for component analysis.

Through the principal component analysis and Varimax orthogonal rotation, we figure out the factor loading of different components whose six eigenvalues are all larger than 1. The results are shown in Table 1.

In component one, the evaluation elements whose factor loadings are larger than 0.6 are $a_{12}, a_{13}, a_{14}, a_{16}, a_{17}, a_{19}$, and $a_{20}$. Because these indexes primarily reflect the job performance, so we name component one job performance component. In component two, the evaluation elements whose factor loadings are larger than 0.6 are $a_{21}, a_{23}$, $a_{24}, a_{28}$, and $a_{30}$; we name component two job capability component. In component three, the evaluation elements whose factor loadings are larger than 0.6 are $a_{1}, a_{3}$, and $a_{6}$ and we name component three working attitude component. In component four, he evaluation elements whose factor loadings are larger than 0.6 are $a_{2}, a_{4}, a_{5}, a_{7}$, and $a_{8}$ and we name component four professional quality component. In component five, the evaluation elements whose factor loadings are larger than 0.6 are $a_{9}, a_{10}$, and $a_{11}$ and we name component five ethnic component. In component six, only two components' factor loadings are larger than 0.6 , that are, $a_{22}$ and $a_{29}$. Because evaluative elements are too little and the job capability has been reflected by component two, so we delete component six. Besides, all factor loadings of $a_{15}, a_{18}$, $a_{25}, a_{26}, a_{27}, a_{31}$, and $a_{32}$ are smaller than 0.6. This means their convergent validities are far from satisfaction, so they should be deleted.

3.2. Determine Index Weight. There are many methods to determine the index weight. In this paper, we use CFA. Reasons are shown as follows. (1) The results of structural equation model are based on many questionnaires whose objectivity can be fully guaranteed compared with other methods which are more subjective. (2) CFA could make further verification of EFA result and make much contribution to ensure the rationality of the performance evaluation structure. (3) The structural equation model could amend the initial model with its dedicated tools to reach the ideal requirements. (4) The structural equation model has been widely used in many performance appraisal systems which are difficult to qualify and performance evaluation index of procurators in this paper is also one difficult to be qualified. So it is reasonable to use this model. (5) Now most researches are using path coefficient obtained through structural equation model to figure out the interaction intensity between components. However, this paper uses the path coefficient obtained through higher CFA model to acquire weight factor. This method has not been frequently used in researches of procuratorial organs' performance appraisal. This has broadened the application of the structural equation model and is fairly innovative.

To conduct CFA, the research group has given out 300 questionnaires to staff in procuratorial organs in JiangXi and teachers in universities and colleges. We finally collect 273 questionnaires and the return rate is $91 \%$. To make the CFA model more rational, this paper will start with oblique factor model and achieve the expecting results through consistent examination and correction.

3.2.1. Oblique Multifactor Model. Supposing there exists correlation between job performance, job capability, working attitude, professional quality, and ethnic, the results of the maximum likelihood method are as follows.

(1) Model Identification. The number of data point is 276 and the amount of estimated parameters is 56. Data point is larger than parameter and DOF is 220. This shows this model is an excessive identification one. So it has met the requirements of SEM model.

(2) Parameter Estimation. The results of standardized estimation of oblique multifactor model are shown in Figure 1. The correlation coefficient between the standardized regression coefficient and latent variable is verified through significance test.

(3) Verification of Incremental Fit Measures. (1) The chisquare value $\left(\chi^{2}\right)$ is 590.811 and the number of $\chi^{2} / d f$ is 
TABLE 1: Rotated component matrix after Varimax orthogonal rotation.

\begin{tabular}{|c|c|c|c|c|c|c|}
\hline \multirow{2}{*}{ Initial evaluation elements } & \multicolumn{6}{|c|}{ Component } \\
\hline & 1 & 2 & 3 & 4 & 5 & 6 \\
\hline$a_{1}$ & 0.142 & 0.091 & 0.654 & 0.33 & -0.173 & -0.237 \\
\hline$a_{2}$ & -0.017 & 0.123 & 0.174 & 0.784 & 0.026 & 0.256 \\
\hline$a_{3}$ & 0.142 & 0.369 & 0.716 & 0.064 & 0.088 & 0.218 \\
\hline$a_{4}$ & 0.115 & 0.058 & 0.223 & 0.783 & 0.157 & -0.13 \\
\hline$a_{5}$ & 0.188 & 0.087 & 0.213 & 0.767 & -0.047 & 0.077 \\
\hline$a_{6}$ & 0.122 & 0.328 & 0.754 & 0.023 & 0.009 & 0.281 \\
\hline$a_{7}$ & 0.104 & 0.116 & 0.151 & 0.692 & 0.072 & -0.02 \\
\hline$a_{8}$ & 0.054 & 0.21 & -0.309 & 0.71 & 0.199 & 0.021 \\
\hline$a_{9}$ & 0.247 & 0.22 & 0.013 & 0.182 & 0.818 & -0.043 \\
\hline$a_{10}$ & 0.176 & 0.197 & 0.013 & 0.099 & 0.829 & 0.101 \\
\hline$a_{11}$ & 0.013 & 0.008 & 0.424 & -0.024 & 0.623 & 0.375 \\
\hline$a_{12}$ & 0.701 & 0.342 & 0.081 & 0.16 & 0.119 & 0.138 \\
\hline$a_{13}$ & 0.678 & 0.196 & 0.03 & 0.347 & 0.119 & 0.27 \\
\hline$a_{14}$ & 0.619 & 0.196 & 0.172 & -0.084 & 0.026 & 0.507 \\
\hline$a_{15}$ & 0.402 & 0.183 & 0.569 & 0.319 & 0.285 & -0.075 \\
\hline$a_{16}$ & 0.768 & 0.341 & 0.257 & 0.06 & 0.108 & -0.006 \\
\hline$a_{17}$ & 0.861 & 0.162 & 0.12 & 0.1 & 0.081 & 0.052 \\
\hline$a_{18}$ & 0.446 & 0.146 & 0.394 & 0.362 & 0.333 & 0.099 \\
\hline$a_{19}$ & 0.765 & 0.107 & 0.105 & -0.032 & 0.102 & 0.215 \\
\hline$a_{20}$ & 0.699 & 0.27 & 0.178 & 0.174 & 0.154 & 0.131 \\
\hline$a_{21}$ & 0.335 & 0.773 & 0.079 & 0.091 & 0.155 & 0.224 \\
\hline$a_{22}$ & 0.448 & 0.247 & 0.011 & -0.076 & 0.024 & 0.712 \\
\hline$a_{23}$ & 0.384 & 0.642 & 0.206 & 0.109 & 0.187 & 0.151 \\
\hline$a_{24}$ & 0.23 & 0.705 & 0.276 & 0.132 & 0.089 & 0.167 \\
\hline$a_{25}$ & 0.456 & 0.4 & 0.212 & 0.234 & 0.25 & -0.001 \\
\hline$a_{26}$ & 0.321 & 0.419 & 0.447 & 0.172 & 0.326 & 0.273 \\
\hline$a_{27}$ & 0.096 & 0.401 & 0.534 & 0.295 & 0.231 & 0.292 \\
\hline$a_{28}$ & 0.362 & 0.687 & 0.336 & 0.226 & 0.208 & 0.046 \\
\hline$a_{29}$ & 0.229 & 0.161 & 0.197 & 0.221 & 0.173 & 0.666 \\
\hline$a_{30}$ & 0.25 & 0.654 & 0.368 & 0.256 & 0.036 & 0.094 \\
\hline$a_{31}$ & 0.262 & 0.231 & 0.508 & 0.191 & 0.29 & 0.366 \\
\hline$a_{32}$ & 0.268 & 0.489 & 0.507 & 0.125 & 0.201 & -0.044 \\
\hline
\end{tabular}

$2.68(590.811 / 220)$. This number is between one and three, meaning that the overall fit measure can meet requirements. (2) The RMR of residual mean square and square root is 0.056 , larger than 0.05 but close to 0.05 . This means that the fit measure is up to requirements. (3) GFI is 0.823 and AGFI is 0.778 . They both fail to meet the ideal requirements. (4) PRATIO (0.87), PNFI (0.669), and PCFI (0.73) are all larger than 0.50 so they can meet the requirements. (5) RMSEA is 0.82 and it means that the fit measure is general.

(4) Internal Quality Evaluation of the Model. (1) Validity reflects the degree of actual measurement of underlying characteristics that target variable that it wants to measure. For SEM model, if the load capacity has reached significance level which means $P$ is smaller than 0.05 and $|t|$ is larger than 1.96, then target variable can effectively reflect the latent variable that it measures and the measurement has high validity. Because all load capacities are smaller than 0 , so this model is of good validity.

(2) Individual observation variable reflects the consistency of measurement and observed variables' multivariate square reflects the reliability of latent variable. It is larger than 0.50 and that means the individual item is reliable. After calculation, among twenty-three measured variables, there are eight individual items whose separation reliability is larger than 0.50 , so this model is qualified.

(3) Composite reliability is also called construct reliability which is used to evaluate the unity of potential construction indicators. Higher composite reliability means higher unity between measurement index and vice versa. The calculation formula is $\rho_{c}=\left(\sum \lambda\right)^{2} /\left[\left(\sum \lambda\right)^{2}+\sum \theta\right] . \rho_{c}$ is composite reliability, $\lambda$ is standardized parameter of observed variable compared with latent variable, and $\theta$ is error variance of target variable. If $\rho_{c}$ is larger than 0.60 , the composite reliability is 


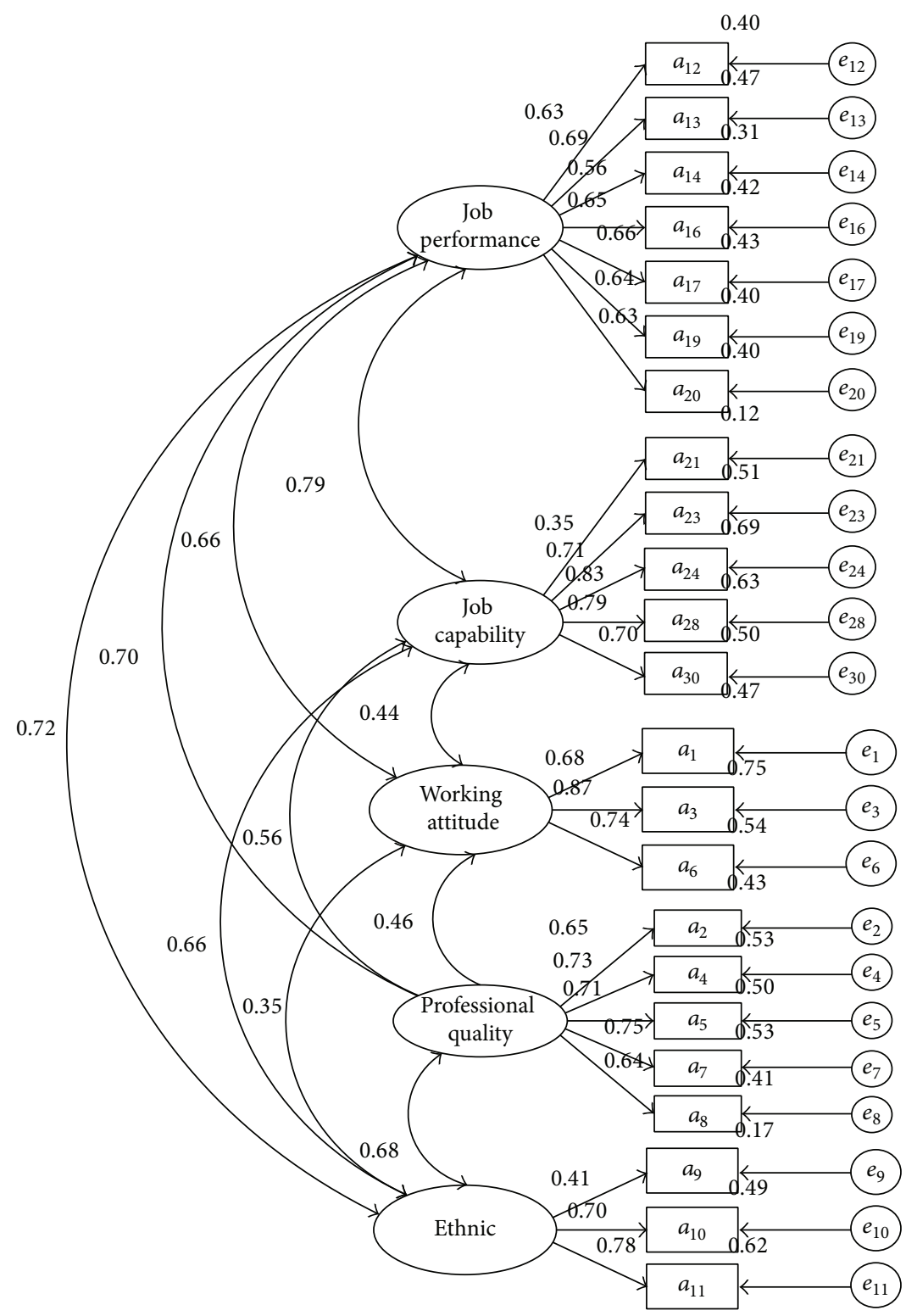

FIGURE 1: Standardized parameter estimates of oblique multifactor model.

qualified. After calculation, we figure out that $\rho_{c 1}=0.827$, $\rho_{c 2}=0.818, \rho_{c 3}=0.808, \rho_{c 4}=0.822$, and $\rho_{c 5}=0.676$. And they, respectively, reflect composite reliability of job performance, job capability, working attitude, professional quality, and ethnic. They are all larger than 0.60 , so this model is of high composite reliability.

(4) Average variance extracted (AVE) indicates variation of target variable which latent variable can explain when compared with the error variance. The calculation formula $\rho_{v}=\sum \lambda^{2} /\left[\sum \lambda^{2}+\sum \theta\right]$ is extracted variance of mean, $\rho_{v}$ is standardized parameter of observed variable on latent variable, and $\theta$ is the error variance of target variable. If $\rho_{v}$ is larger than 0.50 , the observed variable can reflect the latent variable and the latent variable is of high reliability and validity. If $\rho_{v}$ is smaller than 0.50 , the variation of target variable that measuring error can explain is larger than variation that basic latent variable explains. And it means the latent variable has low reliability and validity. After calculation, we figure out that $\rho_{v 1}=0.406, \rho_{v 2}=0.489$, $\rho_{v 3}=0.586, \rho_{v 4}=0.481$, and $\rho_{v 5}=0.426$. And they, respectively, reflect composite reliability of job performance, job capability, working attitude, professional quality, and ethnic. They are all smaller than 0.50 , except $\rho_{v 3}$, and it shows that this model is of low internal quality.

From the external quality inspection (incremental fit measures) and internal quality inspection (reliability and validity test) of oblique multifactor model, we can see that partial incremental fit measures indicator and reliability and validity test indicator are unsatisfactory and needs further improvements. At the same time, correlation coefficient between latent variables shows that the five latent variables have high degree of correlation and there may exist another 


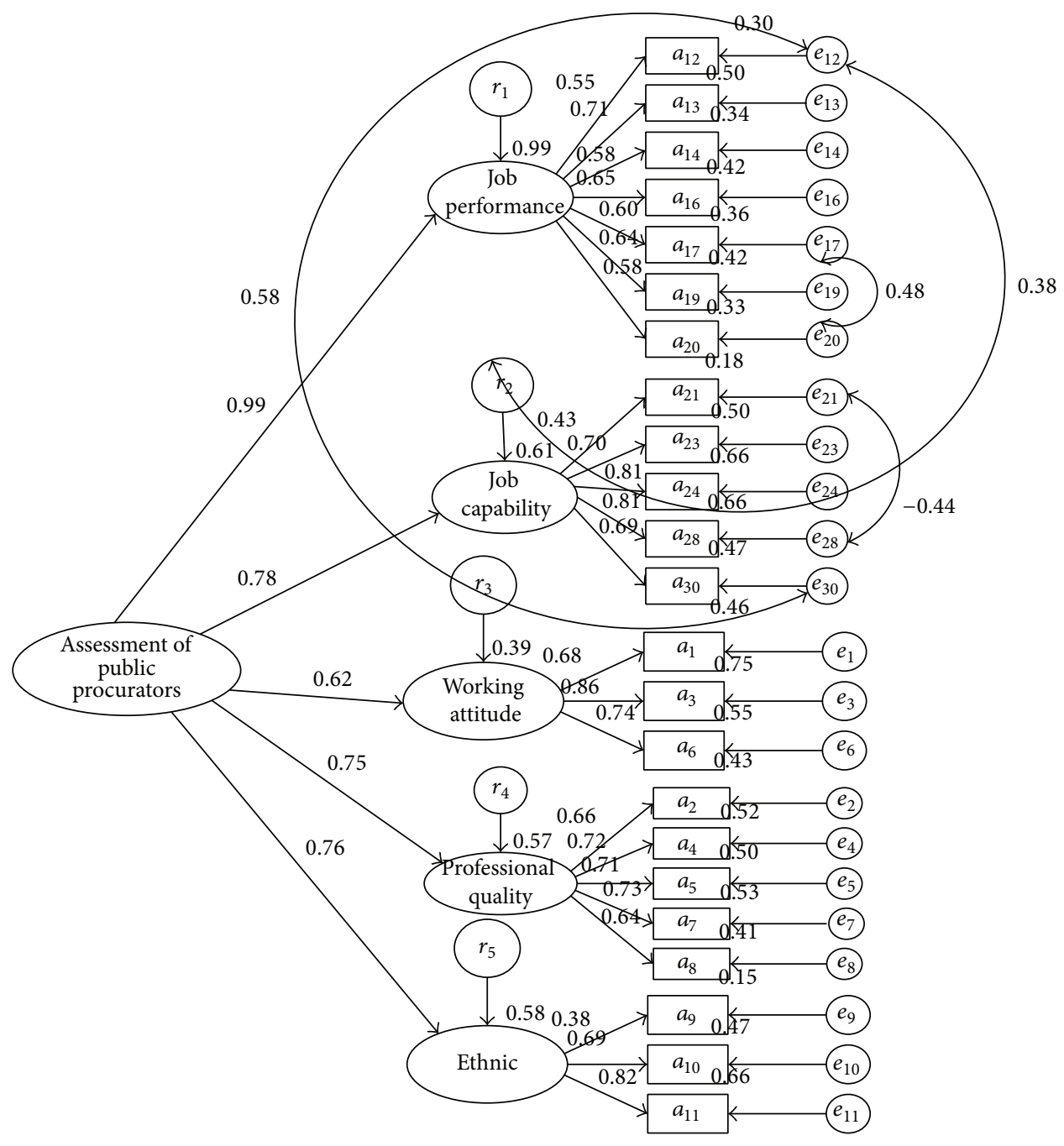

FIGURE 2: Standardized parameter estimates of revised second order CFA models.

high-order common factor. It serves as basis for second order CFA model. So on the basis of oblique multifactor model and needs of appraisal system of procurators, we set up a second order CFA model, make amendments to it, and finally establish the appraisal system of procurators.

3.2.2. Second Order CFA Model. Supposing that job performance, job capability, working attitude, professional quality, and ethnic are all influenced by a high-order component, the five latent variables have transformed into internal latent variables and a new item-estimated residual is added. And we also suppose that there is no error covariation and crossload and each latent variable is only influenced by one firststage component. Then we set up a second order CFA model, modify covariance of the model, release modification indices which are larger than 15 , filter four groups of variables whose critical ratio of error variance is smaller than 0.1 , and restrict a same parameter for them. The results are as follows.

(1) Pattern Recognition. The data points of the model are 276, while parameter estimates in total are 51 . So the data points of the model exceed parameter estimates and the degree of freedom is 225, indicating that this model is the necessary condition of the SEM Model.

(2) Simulation Model Parameter Estimation. Figure 2 presents the standardized parameter estimates of revised second order CFA models. In the diagram, standardized regression coefficient and coefficient of association among the latent variables pass the significance test.

(3) Inspection of Model Adaptation Degree. (1) The chisquare value $\left(\chi^{2}\right)$ is 399.625 and the number of $\chi^{2} / d f$ is $1.776(399.625 / 225)$, which means revised model chi-square significantly decreases, and Chi-square degrees of freedom is between 1 and 3, indicating that fitting degree of the model gets optimized, meeting the requirement. (2) Residual mean square and square RMR are 0.048 , below 0.05 , indicating that fitting degree of the model meets the requirement. (3) Goodness-of-fit index GFI equals 0.870, fixed adaptation degree index AGFI equals 0.840, although not reaching the level of 0.9 , close enough, still meeting the requirement. 
TABLE 2: Appraisal system of prosecutors' performance.

\begin{tabular}{|c|c|c|}
\hline Numbers & Level-1 indicators (weight) & Level-2 indicator (weight) \\
\hline \multirow{7}{*}{1} & \multirow{7}{*}{$\mathrm{A}_{1}:$ Work performance $(0.254)$} & $a_{12}:$ organization in work $(0.127)$ \\
\hline & & $a_{13}:$ ability to make effective solutions $(0.165)$ \\
\hline & & $a_{14}:$ work completed $(0.134)$ \\
\hline & & $a_{16}:$ mistaken case rate $(0.150)$ \\
\hline & & $a_{17}:$ social public satisfaction $(0.139)$ \\
\hline & & $a_{19}:$ ability to successfully meet work expectations $(0.150)$ \\
\hline & & $a_{20}:$ national economic loss redeemed $(0.134)$ \\
\hline \multirow{5}{*}{2} & \multirow{5}{*}{$\mathrm{A}_{2}:$ Work ability $(0.200)$} & $a_{21}:$ willingness and capacity of accepting work training (0.124) \\
\hline & & $a_{23}:$ ability to handle emergencies $(0.205)$ \\
\hline & & $a_{24}:$ ability to contact and to cooperate $(0.236)$ \\
\hline & & $a_{28}:$ ability to employ new knowledge and to adapt to new fields $(0.236)$ \\
\hline & & $a_{30}:$ management ability $(0.200)$ \\
\hline \multirow{3}{*}{3} & \multirow{3}{*}{$\mathrm{A}_{3}:$ Work attitude $(0.159)$} & $a_{1}:$ responsibility in work $(0.297)$ \\
\hline & & $a_{3}:$ positive initiative in work $(0.379)$ \\
\hline & & $a_{6}:$ team spirit $(0.325)$ \\
\hline \multirow{5}{*}{4} & \multirow{5}{*}{$\mathrm{A}_{4}:$ Professional quality $(0.192)$} & $a_{2}:$ abidance by law $(0.189)$ \\
\hline & & $a_{4}:$ abidance by work rules and regulations $(0.209)$ \\
\hline & & $a_{5}:$ abidance by the responsibility of party members $(0.205)$ \\
\hline & & $a_{7}:$ violations of the probations $(0.211)$ \\
\hline & & $a_{8}:$ refusal of the bribe $(0.186)$ \\
\hline \multirow{3}{*}{5} & \multirow{3}{*}{$\mathrm{A}_{5}:$ Ideology and morality $(0.195)$} & $a_{9}:$ political thoughts $(0.204)$ \\
\hline & & $a_{10}:$ level of political theory $(0.364)$ \\
\hline & & $a_{11}$ : outlook of right and wrong and value $(0.432)$ \\
\hline
\end{tabular}

(4) Simple adjustment measure PRATIO equals 0.889 , PNFI equals 0.751, along with PCFI, all above 0.50, meeting the requirement. (5) Gradual residual and square root RMSEA is 0.058 , below uncorrected ones, or between 0.05 and 0.08 , indicating fitting degree of the model fair.

According to the data above, most of goodness-of-fit index of second order CFA models meet the requirement, indicating the external quality of second order CFA Models favorable.

(4) Internal Quality Evaluation of the Model. (1) Validity. All factor loadings in this model are far from 0 , indicating the validity of the model favorable. (2) Individual Item Reliability. Among 28 variables, 13 kinds of individual item reliability are above 0.50 , showing that the internal quality of the model fair. (3) Composite Reliability. The composite reliability result of higher order factor "Assessment of Public Procurators" $\rho_{c}=0.891$. Because $\rho_{c}$ is larger than 0.6 , the overall composite reliability is very ideal. (4) Extracted value of variance of mean of latent variables is AVE. Variance of mean extracted of the higher order factor "Assessment of Public Prosecutors" is 0.627 . The result indicates that this latent variance has favorable reliability and validity.

It is easy to find that most of goodness-of-fit index of revised second order CFA Models meet the requirement, indicating that this model has sound reliability and validity in terms of internal quality assessment. As a result, this model can be set as the final model in the construction of index system.
Final system of assessment of prosecutors' performance can be gained by normalization of path coefficient of revised second order CFA Model, which is shown in Table 2.

\section{Appraisal Instances}

According to the appraisal system of prosecutors' performance above, assessment of prosecutors' performances can be implemented. This research group assesses one prosecutor's performance of a certain procuratorate in Jiangxi Province by taking the fuzzy comprehensive evaluation method based on 360 degrees of main-body evaluation [1113].

(1) Determine Appraisal Factor Aggregation. The appraisal factor aggregation stems from 5 level-1 indicators and 23 level-2 indicators in the performance appraisal system.

(2) Determine Aggregation of Factor Rankings. According to the general principle set by level appraisal aggregation, degree of each kind of indicator can be classified into 5 grades, which are excellent, favorable, medium, pass, and Poor, thus determining the fuzzy judging set $V=\{$ Excellent, Favorable, Medium, Pass, Poor $\}$, according to which, membership sets are, respectively, classified into 95, $85,75,65$, and 55 , and the grade evaluation matrix is $V=$ $[95,85,75,65,55]$. 
TABLE 3: Summary table of primitive matrix of fuzzy comprehensive appraisal for each indicator.

\begin{tabular}{|c|c|c|c|c|c|c|c|c|c|c|c|c|c|c|c|}
\hline \multirow{2}{*}{ Indicators } & \multicolumn{5}{|c|}{ Superior } & \multicolumn{5}{|c|}{ Vis-a-vis } & \multicolumn{5}{|c|}{ Self } \\
\hline & A & B & $\mathrm{C}$ & $\mathrm{D}$ & E & A & B & $\mathrm{C}$ & $\mathrm{D}$ & $\mathrm{E}$ & $\mathrm{A}$ & B & $\mathrm{C}$ & D & E \\
\hline$a_{12}$ & $1 / 5$ & $4 / 5$ & 0 & 0 & 0 & $1 / 5$ & $3 / 5$ & $1 / 5$ & 0 & 0 & 0 & 1 & 0 & 0 & $\overline{0}$ \\
\hline$a_{13}$ & $1 / 5$ & $3 / 5$ & $1 / 5$ & 0 & 0 & $1 / 5$ & $4 / 5$ & 0 & 0 & 0 & 0 & 1 & 0 & 0 & 0 \\
\hline$a_{14}$ & $2 / 5$ & $3 / 5$ & 0 & 0 & 0 & $2 / 5$ & $1 / 5$ & $2 / 5$ & 0 & 0 & 1 & 0 & 0 & 0 & 0 \\
\hline$a_{16}$ & $2 / 5$ & $2 / 5$ & $1 / 5$ & 0 & 0 & $3 / 5$ & $2 / 5$ & 0 & 0 & 0 & 0 & 1 & 0 & 0 & 0 \\
\hline$a_{17}$ & 0 & $4 / 5$ & $1 / 5$ & 0 & 0 & $1 / 5$ & $4 / 5$ & 0 & 0 & 0 & 0 & 1 & 0 & 0 & 0 \\
\hline$a_{19}$ & $1 / 5$ & $3 / 5$ & $1 / 5$ & 0 & 0 & $2 / 5$ & $3 / 5$ & 0 & 0 & 0 & 1 & 0 & 0 & 0 & 0 \\
\hline$a_{20}$ & $2 / 5$ & $3 / 5$ & 0 & 0 & 0 & $3 / 5$ & $1 / 5$ & $1 / 5$ & 0 & 0 & 0 & 1 & 0 & 0 & 0 \\
\hline$a_{21}$ & $3 / 5$ & $2 / 5$ & 0 & 0 & 0 & $2 / 5$ & $3 / 5$ & 0 & 0 & 0 & 1 & 0 & 0 & 0 & 0 \\
\hline$a_{23}$ & $2 / 5$ & $2 / 5$ & $1 / 5$ & 0 & 0 & $3 / 5$ & $2 / 5$ & 0 & 0 & 0 & 0 & 1 & 0 & 0 & 0 \\
\hline$a_{24}$ & 0 & $3 / 5$ & $2 / 5$ & 0 & 0 & $1 / 5$ & $4 / 5$ & 0 & 0 & 0 & 0 & 1 & 0 & 0 & 0 \\
\hline$a_{28}$ & 0 & $4 / 5$ & $1 / 5$ & 0 & 0 & $2 / 5$ & $3 / 5$ & 0 & 0 & 0 & 0 & 1 & 0 & 0 & 0 \\
\hline$a_{30}$ & $3 / 5$ & $2 / 5$ & 0 & 0 & 0 & $3 / 5$ & $2 / 5$ & 0 & 0 & 0 & 1 & 0 & 0 & 0 & 0 \\
\hline$a_{1}$ & $2 / 5$ & $2 / 5$ & $1 / 5$ & 0 & 0 & 0 & $3 / 5$ & $2 / 5$ & 0 & 0 & 0 & 1 & 0 & 0 & 0 \\
\hline$a_{3}$ & $3 / 5$ & $2 / 5$ & 0 & 0 & 0 & $2 / 5$ & $3 / 5$ & 0 & 0 & 0 & 0 & 1 & 0 & 0 & 0 \\
\hline$a_{6}$ & $1 / 5$ & $3 / 5$ & $1 / 5$ & 0 & 0 & $2 / 5$ & $2 / 5$ & $1 / 5$ & 0 & 0 & 0 & 1 & 0 & 0 & 0 \\
\hline$a_{2}$ & $2 / 5$ & $2 / 5$ & $1 / 5$ & 0 & 0 & $1 / 5$ & $2 / 5$ & $2 / 5$ & 0 & 0 & 0 & 1 & 0 & 0 & 0 \\
\hline$a_{4}$ & 0 & $2 / 5$ & $3 / 5$ & 0 & 0 & 0 & $3 / 5$ & $2 / 5$ & 0 & 0 & 0 & 1 & 0 & 0 & 0 \\
\hline$a_{5}$ & $3 / 5$ & $1 / 5$ & $1 / 5$ & 0 & 0 & $2 / 5$ & $3 / 5$ & 0 & 0 & 0 & 0 & 1 & 0 & 0 & 0 \\
\hline$a_{7}$ & $1 / 5$ & $3 / 5$ & $1 / 5$ & 0 & 0 & $2 / 5$ & $2 / 5$ & $1 / 5$ & 0 & 0 & 1 & 0 & 0 & 0 & 0 \\
\hline$a_{8}$ & $3 / 5$ & $2 / 5$ & 0 & 0 & 0 & $2 / 5$ & $3 / 5$ & 0 & 0 & 0 & 1 & 0 & 0 & 0 & 0 \\
\hline$a_{9}$ & $2 / 5$ & $3 / 5$ & 0 & 0 & 0 & $3 / 5$ & $1 / 5$ & $1 / 5$ & 0 & 0 & 0 & 1 & 0 & 0 & 0 \\
\hline$a_{10}$ & $1 / 5$ & $2 / 5$ & $2 / 5$ & 0 & 0 & $2 / 5$ & $2 / 5$ & $1 / 5$ & 0 & 0 & 0 & 1 & 0 & 0 & 0 \\
\hline$a_{11}$ & $2 / 5$ & $2 / 5$ & $1 / 5$ & 0 & 0 & $3 / 5$ & $2 / 5$ & 0 & 0 & 0 & 0 & 1 & 0 & 0 & 0 \\
\hline
\end{tabular}

A, B, C, D, and E, respectively, represent "excellent," "favorable," "medium," "pass," and "poor."

(3) Determine the Appraisal Subject. The thinking of 360degree assessment method being used for reference and in order to make the appraisal result disinteresting, 5 superior prosecutors, vis-a-vis 5 , and the prosecutor itself 1 , making it the total of 11 participants of the fuzzy comprehensive appraisal. Respective weights are determined through discussion among the experts, making the superior 0.6 , vis-a-vis 0.2 and the self 0.2 .

(4) Determine Fuzzy Relation Matrix. Primitive matrix of fuzzy comprehensive appraisal is gained by fuzzy comprehensive appraisal of each main part. See Table 3.

According to the method of fuzzy comprehensive appraisal, the prosecutor's level-1 indicator grades can be computed to be $86.821,86.7725,87.0010,86.5850$, and 86.8560 , making it final grade 86.821, 86.7725, 87.0010, 86.5850 , and 86.8560 and work performance ranking number 2 in the 5 indicators, showing that the most important work performance of the prosecutor is sound in the 4 indicators. Generally speaking, all indicator grades are close. According to the maximum membership principle, the appraisal result of the prosecutor is "favorable." The comprehensive grades of other prosecutors can be gained by employing the same method. The ranking can be important factors for promotion and reward through sorting different prosecutors' grades based on the final grades. In the actual operations, the computation process can be completed by computer software, simplifying the operation process.

\section{Conclusion}

This study combined uses exploratory factor analysis and high-order confirmatory factor analysis to establish the prosecutor performance appraisal system. The study also conducts instance analysis based on 360-degree fuzzy comprehensive appraisal of the main target. Adopting this method is a beneficial trial of using high-order CFA Model, perfecting, and enriching the existing appraisal system of prosecutors' performance and then making the appraisal and evaluation more scientific and reasonable. Meanwhile, such a system built through this thinking not only helps to compare different working indicator result of prosecutors, but also can enlighten what should be corrected and improved. Besides, such a system can make the ranking of various appraisal grades, through which promotion, rewards, and punishments can find their grounds. In practice, it is very operative-oriented because all computations can be accurately done by computers. In the future studies, this system will constitute an important role in further segmenting the appraisal indicators in order to enhance the operability of the indicator system. 
TABLE 4

\begin{tabular}{llrrrr}
\hline \multirow{2}{*}{ Number $\quad$ Evaluation factors } & \multicolumn{3}{c}{ Importance } & & \\
& & 1 & 2 & 4 & 5 \\
\hline
\end{tabular}

(1) Importance based on behaviors

Responsibility in work

Abidance by law in dealing with cases

Positive initiative in work

Abidance by work rules and regulations

Abidance by the responsibility of party members

Team spirit in work

Nonviolations of the probations

Refusal of the bribe

Political thoughts

Level of political theory

Outlook of right and wrong and value

Organization in work

13 Ability to make effective solutions

\begin{tabular}{ll}
\hline 14 & (2) Importance based on results \\
15 & Work completed \\
16 & Mility to finish the duties as required \\
17 & Social public satisfaction \\
18 & Ability to cut litigation cost \\
19 & Ability to successfully meet work expectations \\
20 & National economic loss redeemed \\
\hline & \\
21 & Innovation ability \\
23 & Skills of handling cases \\
24 & Ability to handle emergencies \\
25 & Professional proficiency \\
26 & Professional knowledge \\
27 & Ability to understand and analyze \\
28 & Ability to contact and to cooperate \\
29 & Ability to employ new knowledge and to adapt to new fields \\
30 & English and computer proficiency and operability \\
31 & Ability to manage and control \\
32 & Acute observation
\end{tabular}

\section{Appendix}

\section{A. Questionnaire of Prosecutors' Performance Assessment}

Dear Sir or Madam,

Thank you very much for taking the time out of your busy schedule to fill in this questionnaire! The questionnaire aims to gather information, based on which related factors and incidence influencing a prosecutor's performance can be understood and evaluated in order to provide evidences for the design of assessment system. This questionnaire employs the method of anonymous survey to acquire data which is used only for the study. Therefore, we promise you the confidentiality of all of your provided information. To guarantee the reliability and the validity, please answer the questions according to your actual situation without being affected by other people's opinion. Thanks very much for your cooperation!

There are two parts in the questionnaire. The first part is your personal information and the second is the main part.

A.1. Personal Information. Please mark the " $\sqrt{ }$ " in the brackets.

(1) Gender: male ( ); female ( ) 
(2) Politics status:

Member of communist party of China ( ); general public ( ); democracy parties ( )

(3) Age: under 25 ( ); 26-35 ( ); 36-45 ( ); 46-55 ( ); older than 55 ( )

(4) Education background: senior high school graduates ( ); junior college graduates ( ); undergraduate graduates; postgraduate or above ( )

(5) Ranks or positions: section member ( ); vice section ( ); section chief ( ); deputy director ( ); directing officer ( ).

A.2. Main Part of the Questionnaire. Indicator factors involving behaviors, results, and abilities which possibly influence prosecutors' performances are listed above. Please give your opinion on the importance of each factor by marking " $\sqrt{ }$." Note that "1," " 2 ," and " 3 ," respectively, represent "Dispensable," "Unimportant," "Important," "Necessary," and "Imperative." See Table 4.

\section{Conflict of Interests}

The author declares that there is no conflict of interests regarding the publication of this paper.

\section{References}

[1] O. Bouskila-Yam and A. N. Kluger, "Strength-based performance appraisal and goal setting," Human Resource Management Review, vol. 21, no. 2, pp. 137-147, 2011.

[2] B. Jin, "On the difficult problems of several procuratorial organs performance evaluation," Chinese Prosecutor, no. 11, pp. 3-4, 2010.

[3] O. W. Samuel, M. O. Omisore, and E. J. Atajeromavwo, "Online fuzzy based decision support system for human resource appraisal," Measurement, vol. 55, no. 2, pp. 452-461, 2014.

[4] H. J. Bernardin, J. S. Kane, S. Ross, J. D. Spina, and D. L. Johnson, "Performance appraisal design, development, and implementation," in Handbook of Human Resource Management, Blackwell, Cambridge, Mass, USA, 1995.

[5] D. E. Mathews, "Developing a perioperative peer performance appraisal system," AORN Journal, vol. 72, no. 6, pp. 1039-1042, 1044, 1046, 2000.

[6] K. Geukes, C. Mesagno, S. J. Hanrahan, and M. Kellmann, “Testing an interactionist perspective on the relationship between personality traits and performance under public pressure," Psychology of Sport and Exercise, vol. 13, no. 3, pp. 243-250, 2012.

[7] E. Fichera, S. Nikolova, and M. Sutton, "Comparative performance evaluation: quality," in Encyclopedia of Health Economics, pp. 111-116, 2014.

[8] L. K. Choon and M. A. Embi, "Subjectivity, organizational justice and performance appraisal: understanding the concept of subjectivity in leading towards employees' perception of fairness in the performance appraisal," Procedia-Social and Behavioral Sciences, vol. 62, pp. 189-193, 2012.

[9] D. Lilley and S. Hinduja, "Police officer performance appraisal and overall satisfaction," Journal of Criminal Justice, vol. 35, no. 2, pp. 137-150, 2007.
[10] J. R. Chang, C. H. Cheng, and L. S. Chen, "A fuzzy-based military officer performance appraisal system," Applied Soft Computing, vol. 7, no. 3, pp. 936-945, 2007.

[11] M. Espinilla, R. de Andrés, F. J. Martínez, and L. Martínez, "A 360-degree performance appraisal model dealing with heterogeneous information and dependent criteria," Information Sciences, vol. 222, pp. 459-471, 2013.

[12] S. Thammasitboon, K. Breetz, J. Phillips, and R. Moore, "An innovative 360-degree assessment instrument: using a relative ranking model to enhance the appraisal performance," Academic Pediatrics, vol. 9, no. 4, p. e9, 2009.

[13] R. Sepehrirad, A. Azar, and A. Sadeghi, "Developing a hybrid mathematical model for 360-degree appraisal: a case study," Procedia, vol. 62, no. 12, pp. 844-848, 2012. 


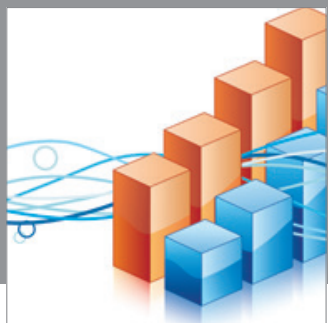

Advances in

Operations Research

mansans

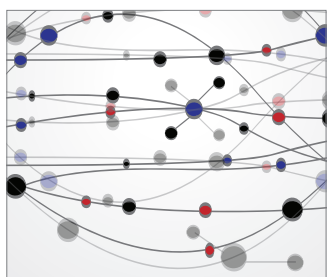

The Scientific World Journal
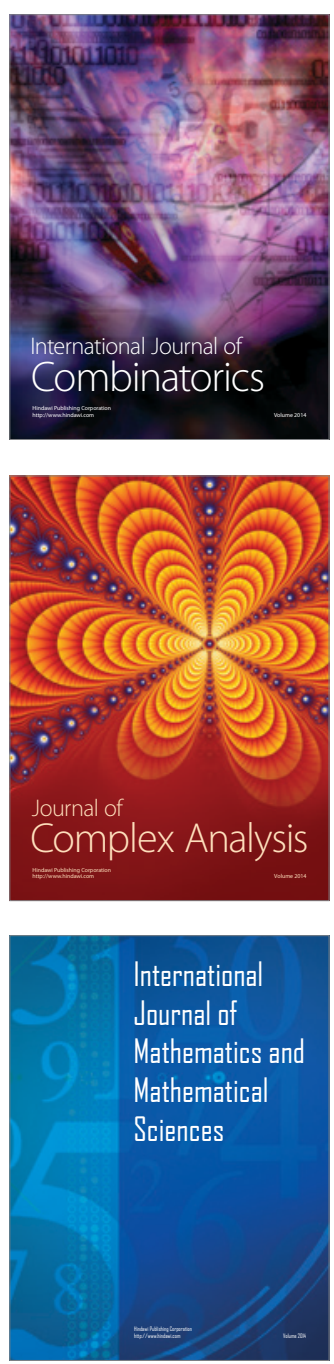
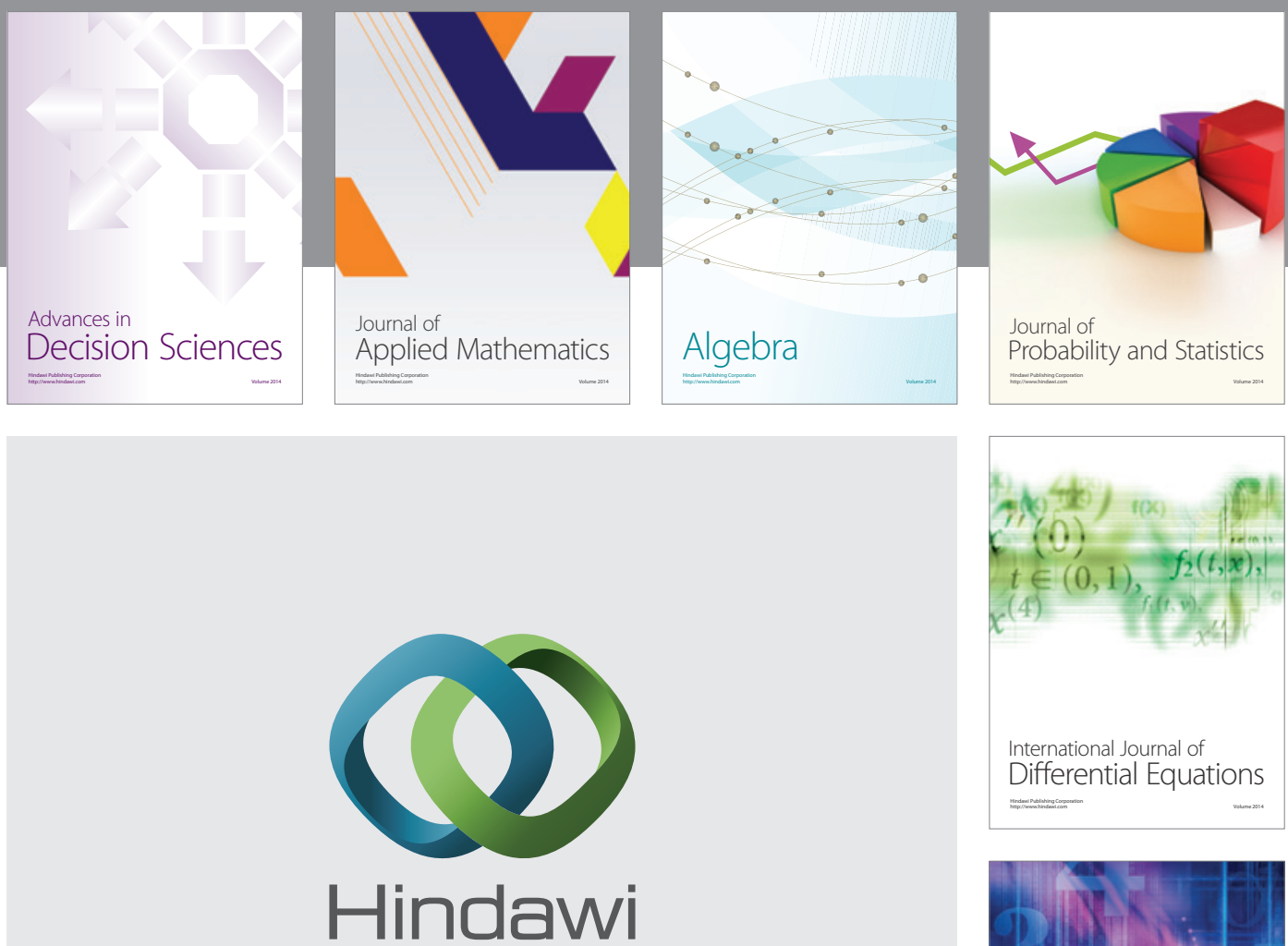

Submit your manuscripts at http://www.hindawi.com
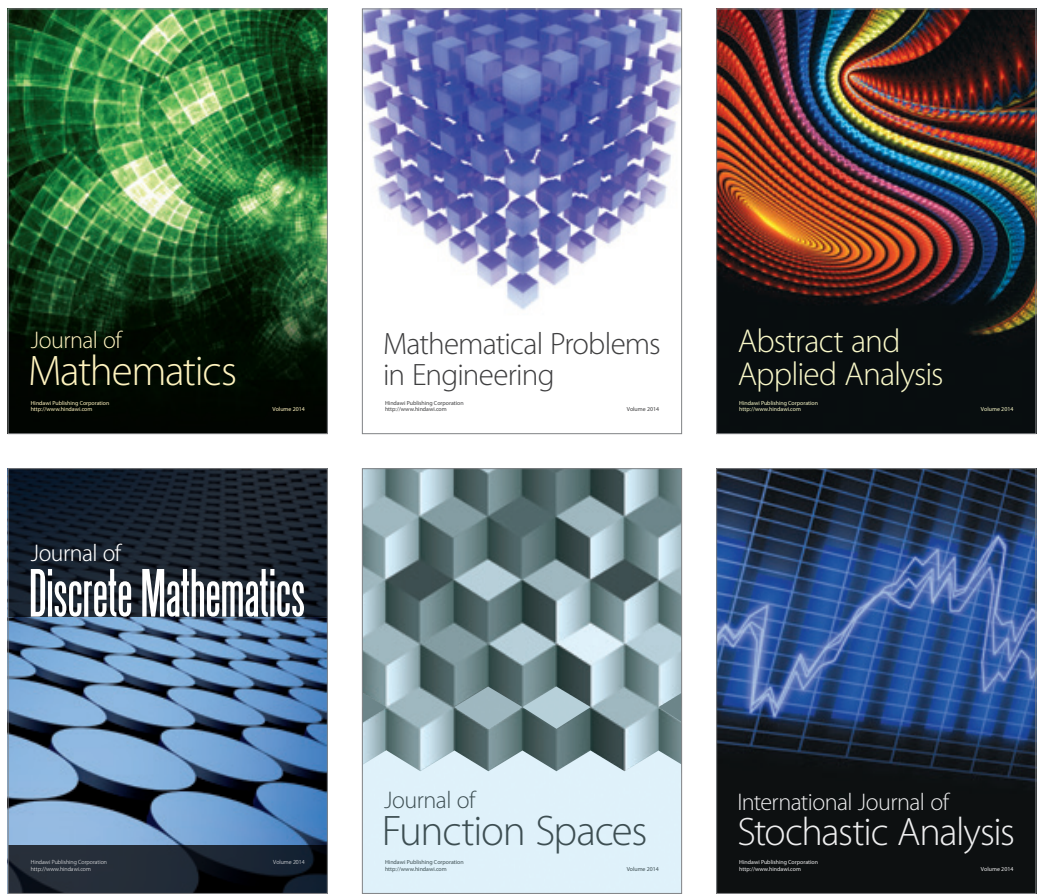

Journal of

Function Spaces

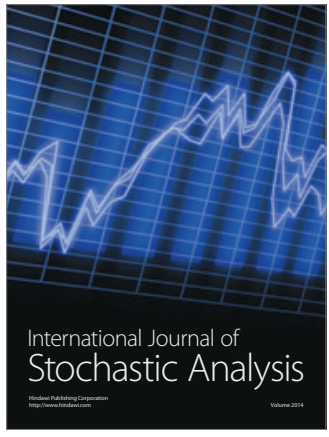

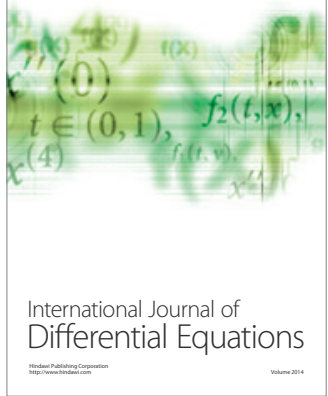
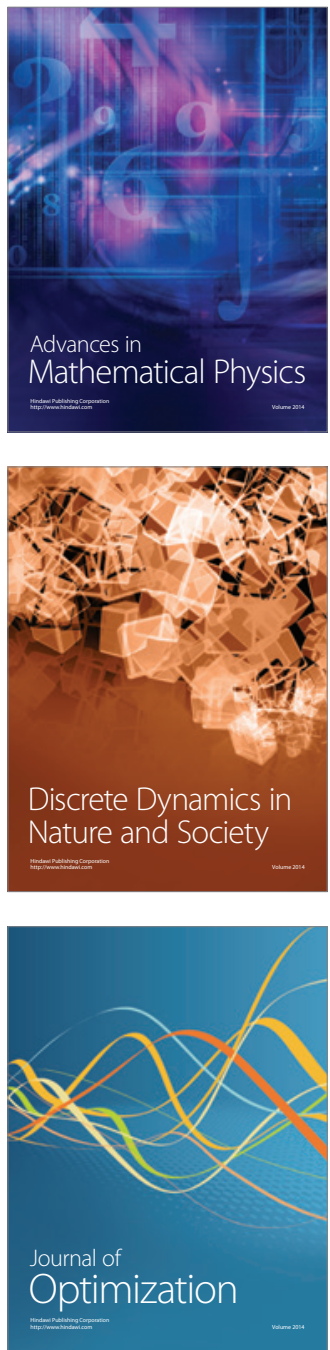